\title{
Comparison of Effects of Different Myofascial Meridians Methods on Pain and Postural Control of College Students with Forward Head Posture
}

\author{
Byeong-Hoon Song, PT, MS • Yoon-Hee Choi, PT, MS ${ }^{1}$ Yong-Jun Cha, PT, $\mathrm{PhD}^{2 \dagger}$ \\ Department of Physical Therapy, Daejeon CL Hospital \\ 'Department of Physical Therapy, Graduate School, Daejeon University \\ ${ }^{2}$ Department of Physical Therapy, College of Health and Medical Science, Daejeon University
}

Received: September 28, 2018 / Revised: October 2, 2018 / Accepted: October 26, 2018

(C) 2019 J Korean Soc Phys Med

\section{| Abstract |}

PURPOSE: This study was conducted to investigate the effects of the myofascial meridians release technique on pain and postural control of college students with forward head posture and to compare the intervention effects of the Grastone massage and the Rollfing massage.

METHODS: Thirty subjects with forward head posture were randomly and equally allocated to experimental group I (myofascial meridians release technique using Grastone massage, $\mathrm{n}=15$ ) or experimental group II (myofascial meridians release using Rollfing massage, $n=15$ ). All subjects underwent 30 minutes of different myofascial meridians release techniques in addition to general physical therapy (hot pack: $15 \mathrm{~min}$, interferential current therapy: $15 \mathrm{~min}$, ultra sound: $5 \mathrm{~min}$ ) three times a week for a total of 6 weeks. Outcome was measured before and after 4 weeks of

†Corresponding Author : Yong-Jun Cha cha0874@dju.kr, https://orcid.org/0000-0002-8553-7098

This is an Open Access article distributed under the terms of the Creative Commons Attribution Non-Commercial License (http://creativecommons.org/licenses/by-nc/3.0) which permits unrestricted non-commercial use, distribution, and reproduction in any medium, provided the original work is properly cited. intervention.

RESULTS: In both groups, the numerical rating scale of pain was significantly decreased after intervention, with experimental group I showing a greater decrease than experimental group II. The neck disability index decreased significantly after intervention in both groups, with experimental group I showing a significantly greater decrease than the controls. The distance of the head forward displacement did not differ significantly between the two groups ( $\mathrm{p}>.05)$.

CONCLUSION: This study suggests that the Grastone method combined with the myofascial meridians release technique is a more effective intervention for improvement of pain and postural control in adults with moderate forward head posture.

Key Words: Myofascial meridians release, Pain, Posture, Forward head posture

\section{Introduction}

The seven bones in the cervical spine have more mobility than those in the thoracic and lumbar spines and these bones support the head, which weighs up to $6 \mathrm{~kg}$ on average; 
therefore, they are very sensitive and easily damaged[1,2]. Smart phones, netbooks, and wearable small electromagnetic devices are providing convenience, but also have many side effects[3,4]. The majority (97.4\%) of people in their $20 \mathrm{~s}$ use such devices, which is more frequent than for other age groups[5]; however, the use of electronic devices for long periods of time can cause the position of the head to shift to the front and cause forward head posture[6].

Forward head posture causes the center of the head to move in the anterior direction, resulting in concentration of anterior cervical vertebral support. This increases the lordotic curve of the head and neck joints and increases the tension and pain of the muscles under the shoulder and occipital bones[7,8]. To alleviate the symptoms associated with short hamstring syndrome, various intervention methods such as stretching exercise, antagonist strengthening exercise, soft tissue mobilization, and fascia relaxation have been conducted[9].

Myofascial meridians release (MMRA) by the Rolfing massage, a technique of fascia relaxation, is a method in which the fascia is gently pulled and relaxed by hand along the myofascial meridian until a slight resistance is felt. This technique is effective at increasing blood and lymphatic circulation[10], as well as improving range of motion and reducing pain[11]. It is particularly useful for normalizing the cervical tilting angle of patients with chronic forward head posture, and is effective at improving spine alignment and reducing shoulder and back pain in patients with thorax and lumbar scoliosis[12,13].

Soft tissue manipulation using a Grastone made of stainless steel is a soft tissue operation suitable for treatment of fibrosis and inflammatory diseases. The Grastone releases mechanically damaged connective tissue from normal tissue and generates a fine amount of microcracks at the treatment site to rearrange the degenerative connective tissue, increase fibroblast and collagen production, improve functional movement and reduce pain $[14,15]$.

The myofascial meridians release technique is known to be effective at improving function and reducing the pain of subjects with forward head posture[16]. However, most studies that have demonstrated the effectiveness of the myofascial relaxation technique have focused on hand massage[11,16]. In addition, no studies of the effects of the Grastone method on the myofascial relaxation technique have been conducted, even though soft tissue manipulation using Grastone positively affects muscle-like connective tissues, joints and pain. Therefore, this study compared the therapeutic effects of massage-assisted myofascial meridians release and Grastone-assisted myofascial meridians release in individuals in their twenties with forward head posture. Additionally, suggestions for more effective myofascial meridians release techniques for decreasing pain and improving postural control are made.

The specific hypotheses of this study are as follows. Application of the myofascial meridians release technique using the Rollfing massage and the Grastone methods will effectively improve postural control ability and reduce pain in adults with forward head posture. Second, the myofascial meridians release technique using the Grastone method will be more effective than the Rollfing massage.

\section{Methods}

\section{Subjects}

This subjects of this study were college students in D University in D city. The criteria for the selection of the subjects were those who had neck and shoulder pain for more than 6 months and who had a numeral rating scale (NRS) of 5 or more, a Korean version of the neck disability index (KNDI) of more than 5 points, and a shift in the center of the ear to more than $2.5 \mathrm{~cm}$ forward from the center of the shoulder. Individuals who experienced neck and shoulder injury within the last 3 months, had inflammation of the spinal joint, or had undergone orthopedic surgery of the spine were excluded.

A total of 30 subjects were selected and the purpose of this study was fully explained to them. All subjects 

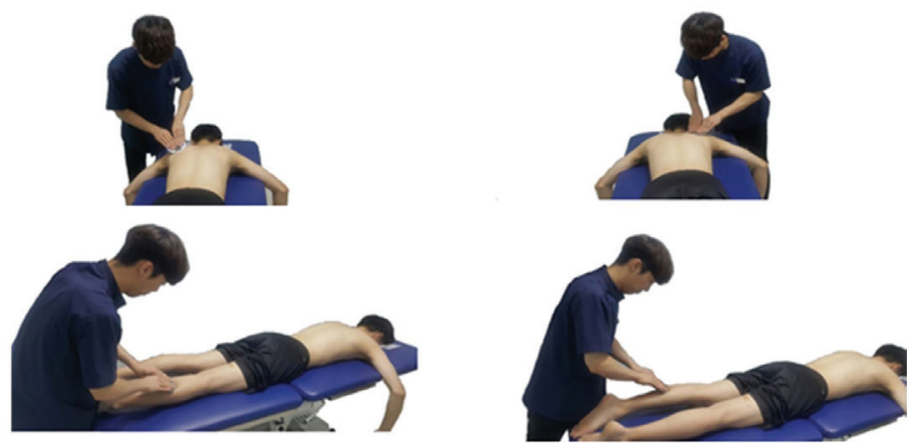

Fig. 1. Myofascial meridian relaxation using the Grastone method.

voluntarily agreed to participate in the experiment. This study was conducted after approval from the D University Research Ethics Review Committee.

\section{Procedures}

A total of 30 subjects were randomly assigned to experimental group I ( $\mathrm{n}=15$; myofascial meridians release using the Grastone) and experimental group II ( $\mathrm{n}=15$; myofascial meridians release with Rollfing massage) by random sampling. Before applying the myofascial meridians release technique, physiotherapy (hot pack, interferential current therapy, ultra-sound therapy) was performed on the neck or shoulder with discomfort for 35 minutes. In addition, the Grastone method or Rollfing massage was added to each myofascial meridians release technique for 30 minutes. One physical therapist applied each treatment. All interventions were conducted three times a week for a total of four weeks.

\section{1) Myofascial meridians release technique}

The myofascial meridian of the human body can be divided into six regions. The surface posterior line controls most postures and movements in the sagittal plane, and controls and limits the flexion of the anterior surface line [17]. Subjects with forward head posture showed extension of the upper part of the occiput and upper cervical subluxation because of limitation of the operation of the lower part of the occipital bone. Therefore, in this study, myofascial meridian relaxation technique was applied to the superficial back line (SBL) as shown in Table 1. When applying a myofascial meridian relaxation method to a subject, larger pain should not be induced.

\section{2) Myofascial meridian relaxation using the Grastone method}

To relax the myofascial meridian using the Grastone method, the subject was placed in a prone position while relaxed on a table (Fig. 1). Using the Grastone (Balancebody, Korea), the myofascial line was relaxed in the order of the bone attachment points on the posterior surface of the upper (1-8) and lower limbs (9-13) along the path of the myofascial[18]. For application to the lower extremities, myofascial meridian relaxation using the Grastone started from the plantar fascia and short toe flexors and continued to the sacrotuberous ligament. The reciprocal movement was 30 times for 60 seconds per section of the myofascial meridian and the visual analogue scale (3) was utilized to maintain constant control of the tool pressure.

\section{3) Myofascia meridian relaxation by Rollfing massage}

To apply the myofascial meridian relaxation technique to the myofascial meridian using the Rollfing massage, the subject was placed in a prone position on the table. 
Table 1. Myofascial Meridians Release Fechnique

\begin{tabular}{|c|c|c|c|}
\hline & Bony station & & Myofascial tracks \\
\hline \multirow{5}{*}{ Upper limb } & Frontal bone/Supraorbital ridge & 13 & \multirow{3}{*}{ Galea aponeurotica/Epicranical fascia } \\
\hline & & 12 & \\
\hline & \multirow[t]{2}{*}{ Occipital ridge } & 11 & \\
\hline & & 10 & \multirow[t]{2}{*}{ Sacrolumbar fascia/Erector spinae } \\
\hline & Sacrum & 9 & \\
\hline \multirow{8}{*}{ Lower limb } & & 8 & Sacrotuberous ligament \\
\hline & \multirow[t]{2}{*}{ Ischial tuberosity } & 7 & \\
\hline & & 6 & Hamstrings \\
\hline & \multirow[t]{2}{*}{ Condyles of femur } & 5 & \\
\hline & & 4 & Gastrocnemius/Achilles tendon \\
\hline & \multirow[t]{2}{*}{ Calcaneus } & 3 & \multirow{3}{*}{ Plantar fascia/Short toe flexors } \\
\hline & & 2 & \\
\hline & Plantar surface of toe phalanges & 1 & \\
\hline
\end{tabular}

The fascia was then palpated to feel its imbalance, nature, and temperature, and the fascia layer in which the muscles deviated from the fascia due to muscle tension was identified[19]. The rubbing method (stroking), which is a gentle stroking massage technique using the entire palm with the same procedure as for the myofascial meridian release using the Grastone, was then employed.

\section{Outcome measures}

\section{1) Pain}

A numerical rating scale (NRS) was used to assess pain based on the visual analog scale before and after intervention. This test tool divides a straight line numbered from 0 to 10 into 11 steps to express the patient's own pain or discomfort in numbers[20]. A score of 0 means no pain, 10 means unimaginable pain, 1 to 4 is mild pain, 5 to 6 is moderate pain, and 7 or more is severe pain. A 2-point or $30 \%$ reduction in the pain score indicates that the pain is improved[21]. The reliability of the inter-rater of numerical pain grades ranged from .95 to .96 , with a validity score of .86 or higher[22].

\section{2) Neck disability index}

The Korean version of the neck disability index was used to assess dysfunction of the neck before and after intervention. This test tool, which is used to assess the degree of abnormality of the neck, was developed to assess the level of daily living limitation[23]. The neck disability dysfunction index consists of 10 items related to intensity of pain, lifting, concentration, reading, headache, personal care, driving, sleeping, and leisure activities. The total score is 50 points, with a higher score indicating higher severity of the neck disorder[24]. A score of 0 to 4 points indicates no disorder, 5 to 14 indicates mild disorder, 15 to 24 indicates moderate disorder, 25 to 34 indicates severe disorder, and 35 or more indicates complete disorder. The cervical disability index is highly reliable, with a Cronbach's a of .90[23].

\section{3) Measurement of the forward movement distance of the head}

The distance between the center of the ear and the center of the shoulder was measured before and after the intervention. To measure the distance, a sliding caliper ( $\mathrm{T}$ 
Table 2. General characteristics of all subjects

\begin{tabular}{cccc}
\hline Demographic features & Experimental group I $(\mathrm{n}=15)$ & Experimental group I II $(\mathrm{n}=15)$ & $\mathrm{x}^{2} / t$ \\
\hline Sex (male/female) & $4 / 11$ & $5 / 10$ & .386 \\
Age (years) & $19.80 \pm 1.47$ & $19.26 \pm 2.40$ & .732 \\
Height $(\mathrm{cm})$ & $166.94 \pm 7.13$ & $165.92 \pm 9.70$ & .328 \\
Weight $(\mathrm{kg})$ & $60.90 \pm 9.38$ & $60.86 \pm 10.57$ & .009 \\
\hline
\end{tabular}

Values are expressed as the means \pm standard deviations or frequencies

Table 3. Comparison of Numerical Rating Scale before and after Intervention Within Each Group and between Groups

\begin{tabular}{ccccc}
\hline & & Experimental group I $(\mathrm{n}=15)$ & Experimental group I II $(\mathrm{n}=15)$ & $t$ \\
\hline & Pre & $6.40 \pm .91$ & $6.20 \pm .94$ & 0.592 \\
NRS & Post & $1.66 \pm .81$ & $2.66 \pm 1.75$ & $-1.997^{*}$ \\
$($ Score $)$ & $t$ & 14.99 & 7.26 & $2.069^{*}$ \\
& Change & $4.73 \pm 1.22 *$ & $3.53 \pm 1.88^{*}$ & 2 \\
\hline
\end{tabular}

NRS, numerical rating scale ${ }^{*} p<.05$

\& B, USA) was used while the subject was placed in a comfortable sitting position on a chair. The measurer adjusted the base point of the sliding caliper plate to the center of the ear, and measured the distance between the center of the shoulder and the center of the ear on the side. To find the outermost protruding area of the acromion process, the center of the shoulder, the measurer stands behind the subject and holds both acromion processes at the same time with the first finger. The first finger was then moved slightly to the center of the shoulder, and the outermost portion of the shoulder bone was regarded as the center of the shoulder[25].

\section{Data analysis}

All collected data were analyzed using SPSS for Windows 20.0. After regularity tests of all data, independent sample t-tests and Chi-square exact tests were conducted to compare the general characteristics of the subjects. A comparative sample t-test was used to compare the mean differences before and after intervention. Independent sample t-tests were performed to compare the changes before and after intervention. Statistical significance was set at .05 .

\section{Results}

\section{General characteristics of subjects}

There were no significant differences in general characteristics such as sex, age, height, and body weight between the two groups. Table 2 shows the general characteristics of the subjects

\section{Comparison of pain before and after} intervention in both groups by numerical rating scale

Table 3 shows the results of the numerical rating scale (NRS) for neck and shoulder pain before and after intervention in both groups. Both groups showed significant decreases in neck and shoulder pain after intervention compared to before intervention. The score of experimental 
Table 4. Comparison of Neck Disability Index before and after Intervention Within Each Group and between Groups

\begin{tabular}{ccccc}
\hline & & Experimental group I $(\mathrm{n}=15)$ & Experimental group I II (n=15) & $t$ \\
\hline \multirow{2}{*}{ NDI } & Pre & $12.06 \pm 1.43$ & $12.86 \pm 2.85$ & -.971 \\
$($ score $)$ & Post & $2.93 \pm 1.48$ & $4.06 \pm 2.84$ & -1.369 \\
& $t$ & 18.40 & 11.82 & $0.373^{*}$ \\
\hline
\end{tabular}

NDI, neck disability index

$* p<.05$

Table 5. Comparison of Posture Assessment before and after Intervention Within each Group and between Groups

\begin{tabular}{ccccc}
\hline & & Experimental group I $(\mathrm{n}=15)$ & Experimental group I II $(\mathrm{n}=15)$ & $t$ \\
\hline \multirow{2}{*}{$\begin{array}{c}\text { Sliding } \\
\text { caliper }\end{array}$} & Pre & $4.20 \pm 0.61$ & $4.16 \pm 0.93$ & .138 \\
$(\mathrm{~cm})$ & $t$ & $2.74 \pm 0.91$ & $2.80 \pm 1.05$ & -.167 \\
& Post & 5.45 & 5.68 & .280 \\
\hline
\end{tabular}

$\mathrm{SC}$, sliding caliper

${ }^{*} p<.05$

group I decreased by 1.2 that of experimental group I II $(\mathrm{p}<.05)$

\section{Comparison of neck disability index before and} after intervention

Table 4 shows the prevalence of cervical disability before and after intervention. Both groups showed a significant decrease in cervical disability index after intervention compared to before intervention. The score of experimental group I was .4 score more significant decrease than that of experimental group I II $(\mathrm{p}<.05)$.

\section{Comparison of the distance of head forward movement between before and after intervention}

Table 5 shows the results of the comparison of the forward movement distances of the head before and after intervention. Both groups showed a significant decrease in the distance of forward movement of the head after intervention compared to before intervention. There was no significant difference between the two groups $(\mathrm{p}>.05)$.

\section{Discussion}

This study was conducted to compare the effects of Grastone and Rolling massage on pain and postural changes in college students with moderate forward head posture. Myofascial meridians release using the Grastone and Rollfing Massage reduced neck and shoulder pain and cervical dysfunction, and had a positive effect on normalization of cervical posture. Application of the Grastone technique was more effective for neck and shoulder pain and neck dysfunction than Rollfing massage. Upon comparison of pain using the visual analogue scale, both groups showed significant decreases in neck and shoulder pain after intervention, with a greater decrease occurring in the Grastone group than the Rollfing massage group.[26,27] Reported that the soft tissue relaxation technique using the Grastone method effectively reduced pain in chronic neck pain patients, and was effective at 
reducing shoulder pain in patients with myofascial pain syndrome. This is because the delicate and precise stimulation of the Grastone method applied along the myofascial meridians rearranges the fascia of the tissue and reduces tension in the muscle fibers[14]. Their results are consistent with those of the present study.

The neck disability index decreased significantly in both groups, with the Grastone group showing a greater decrease than the Rollfing group. Induction of minor damage of the capillary vessels using fascia relaxation tools is effective at inducing rapid normalization of the deep tissue and fascia [16,28]. Kim [12] and Park [29] reported that application of the myofascial relaxation technique using a tool has a significant effect on reduction of the neck disability index in patients with chronic neck pain. These results support the findings of the present study, in which oblique and rounded Grastone tools were more effective at reducing the disability index than Rollfing massage.

There was no significant difference in the distance between the center of the ear and the center of the shoulder between groups. Previous studies suggested that sustained and constant pressure transfer of the muscles using a compression tool could increase the range of motion because it is effective at inducing intermittent muscle contraction and decreasing muscle tone[16,30]. Cheon[13] reported that the fascia meridians relaxation technique was effective at improving cervical tilt and body shape. Overall, the results of these previous studies are in accordance with those of the present study in that the distance from the center of the ear to the shoulder center was reduced.

This study was aimed at young college students in their twenties who are able to conduct daily activities without any difficulty. Therefore, it is difficult to generalize the effects of intervention to patients with turtle syndrome. In addition, the results of the intervention for a relatively short period of 4 weeks and lack of follow up were considered to be limitations of this study. Nevertheless, this study is of clinical value because it is the first to investigate the effects of fascia meridians relaxation using a therapeutic tool on patients with forward head posture. It is necessary to clarify the effects of interventions by testing subjects of different ages and various symptoms that complement the limitations of this study.

\section{Conclusion}

This study was conducted to investigate the effects of myofascial meridians release technique combined with Grastone and Rollfing massage on neck and shoulder pain and posture change and to compare the effects of two fascia meridians release techniques. Application of the myofascial meridians release technique using the Grastone and Rollfing massage effectively improved the pain, dysfunction, and posture change of the neck and shoulder of subjects with forward head posture. Moreover, use of the Grastone technique was more effective than Rollfing massage. Therefore, the Grastone method is considered to be a useful technique to relieve pain and weakness of the neck and shoulder of subjects with moderate forward head posture.

\section{References}

[1] Bland JH, Boushey DR. Anatomy and physiology of the cervical spine. Semin Arthritis Rheum. 1990; 20(1):1-20.

[2] Cynthia C, Norkin, Pamela, et al. Joint Structure \& Function. 2nd Ed: FA Davis Co. 1992.

[3] Kim SH, Kim KU. Changes of cervical angle according to smartphone using time. J Korean Soc Phys Med. 2014;9(2):141-9.

[4] Pacheco J, Raimundo J, Santos F, et al. Forward head posture is associated with pressure pain threshold and neck pain duration in university students with subclinical neck pain. Somatosens Mot Res. 2018:8(1):1-6.

[5] Korea Communications Commission. Survey research on smart phone use. Seoul: Korea Internet \& Security 
Agency. 2012.

[6] Lewis JS, Valentine RE. Clinical measurement of the thoracic kyphosis. A study of the intra-rater reliability in subjects with and without shoulder pain. BMC Musculoskelet Disord. 2010;Mar(1):11-39.

[7] Kim YH, Khil JH. Effects of exercise training and chiropractic on grip strength and cervical muscle strength of subjects with forward head posture and turtle neck. J Korean Soc Phys Med. 2017;12(2):121-7.

[8] Luedtke K, Boissonnault W, Caspersen N, et al. International consensus on the most useful physical examination tests used by physiotherapists for patients with headache: A Delphi study. Man Ther. 2016;Jun(23): 17-24.

[9] Castellote-Caballero Y, Valenza MC, Martin-Martin L, et al. Effects of a neurodynamic sliding technique on hamstring flexibility in healthy male soccer players. A pilot study. Phys Ther Sport. 2013;14(3):156-62.

[10] Stanley S, Dennis JD. Myofascial (soft tissue) techniques: An osteopathic approach to diagnosis and treatment. 3rded. Lippincott Williams\& Wilkins. 2005.

[11] Hussey MJ, Boron-Magulick AE, Valovich McLeod TC, et al. The Comparison of Instrument-Assisted Soft Tissue Mobilization and Self-Stretch Measures to Increase Shoulder Range of Motion in Overhead Athletes: A Critically Appraised Topic. J Sport Rehabil. 2018;27(4): 385-9.

[12] Kim TY. The Effect of the myofascial manual therapy on functional scoliosis in adult. Master's Degree. Cha University. 2018.

[13] Cheon SH. The Effects of Myofascial Meridians Therapy on Changes in Slope of Cervical Vertebrae. Master's Degree. Soongsil University. 2012.

[14] Fowler S, Wilson JK, Sevier TL, et al. Innovative approach for the treatment of cumulative trauma disorders. Work. 2000;15(1):9-14.

[15] Howitt S, Wong J, Zabukovec S, et al. The conservative treatment of Trigger thumb using Graston Techniques and Active Release Techniques. J Can Chiropr Assoc. 2006; 50(4):249-54.

[16] Portillo-Soto A, Eberman LE, Demchak TJ, et al. Comparison of blood flow changes with soft tissue mobilization and massage therapy. J Altern Complement Med. 2014;20(12):932-6.

[17] Thomas W. Myers. Anatomytrain: Myofascial meridians for manual and movement therapists. Elsevier. 2014.

[18] Han NH. The effect of myofascial meridians release approach on gait and balance in patients with stroke. Graduate School of Biomedical Science. Master's Degree. Korea University. 2014.

[19] Choi SP, Song YK, Lim HH. The anatomy trains 12-session recipe (ATR). J Korea CHUNA Man Med. 2005; 6(1):59-66.

[20] Salaffi F, Stancati A, Silvestri CA, et al. Minimal clinically important changes in chronic musculoskeletal pain intensity measured on a numerical rating scale. Eur J Pain. 2004;8(4):283-91.

[21] Cleland JA, Childs JD, Whitman JM, et al. Psychometric properties of the neck disability index and numeric pain rating scale in patients with mechanical neck pain. Arch Phys Med Rehabil. 2008;89(1)69-74.

[22] Hawker GA, Mian S, Kendzerska T. Measures of adult pain: visual analog scale for pain (VAS pain), numeric rating scale for pain (NRS pain), McGill pain questionnaire (MPQ), short-form McGill pain questionnaire (SF-MPQ), chronic pain grade scale (CPGS), short form-36 bodily pain scale (SF-36 BPS), and measure of intermittent and constant osteoarthritis pain (ICOAP). Arthritis Care Res. 2011;63(11): 240-52.

[23] Vernon H, Mior S. The Neck Disability Index :A study of reliability and validity. J Manipulative Physiol Ther. 1991;14(7):409-15.

[24] Bovim G, Schrader H, Sand T. Neck pain in the general population. Spine. 1994;19(12):1307-9.

[25] Kim YJ. Effect of ballet program on turtle neck syndrome in office workers. Master's Degree. Hanyang 
University. 2010.

[26] Lee DW. The Effect of myofacial release and Grastone technique on pain and cervical ROM in 20's age with chronic neck pain. J Green Res. 2013;19(2):77-84.

[27] Heo HR. The effect of meridian muscle release and Graston technique on pain and functional movement in patient with myofascial pain syndrome of shoulder joint. Master's Degree. Sahmyook University. 2018.

[28] Cheatham SW, Lee M, Cain M, Baker R. The efficacy of instrument assisted soft tissue mobilization: a systematic review. J Can Chiropr Assoc. 2016;60(3): 200-11.

[29] Park HW. Effects of Fascial Relaxation Massage Using a Vibration Massage Device on Stress and Neck Pain. Graduate School of Manipulative Therapy. Master's Degree. Kyonggi University. 2018.

[30] Fryer G, Pearce AJ. The effect of lumbosacral manipulation on corticospinal and spinal reflex excitability on asymptomatic participants. J Manipulative Physiol Ther. 2012;35(2):86-93. 
